\title{
LARGE SCALE VERTICAL ELECTRICAL SOUNDINGS SURVEY IN ANTHEMOUNTAS RIVER BASIN FOR EVALUATING HYDRAULIC COMMUNICATION BETWEEN SUB BASIN AQUIFERS
}

\author{
Vargemezis G. ${ }^{1}$ and Fikos $\mathbf{I}^{1}{ }^{1}$ \\ ${ }^{1}$ Aristotle University of Thessaloniki, Department of Geology, Laboratory of Applied Geophysics, 54124 \\ Thessaloniki,Greece,varge@geo.auth.gr,ifikos@geo.auth.gr
}

\begin{abstract}
In Anthemountas river basin a number of studies have taken place mainly because of the significant drop of underground water level observed in the beginning of the last decade. Data from existing hydrowells show the existence of a complex aquifer with the two main underground water bodies situated east and west of the region of Vasilika and Galarinos villages respectively. A large scale geophysical survey took place consisting of Vertical Electrical Soundings (VES) and Electrical Resistivity Tomography (ERT). The main area of interest is in the central region of the basin between Vasilika and Galarinos villages where eighty five (85) VES (Schlumberger array), located on a regular grid revealed a three dimensional model for the sedimentary formations while mapping the bedrock down to a depth of more than $600 \mathrm{~m}$ has been achieved. In the same area, ERT measurements and geological information derived from borehole data are used to obtain a more detailed geological model for the area of interest. From surface to bedrock depth, the hydraulic communication between these two water bodies is examined. Furthermore significant geological features are observed and discussed.
\end{abstract}

Key words: Vertical Electrical Soundings, complex aquifer, Anthemountas river basin.

\section{Introduction}

In previous decades the increasing urban development along with intense agricultural activity in Anthemountas river basin resulted in significant drop of underground water level. With the support of local authorities, many scientists focused their interest on the broader area and studied the geological and the hydrogeological setting (IGME 1996, Nagoulis 1998, Theodossiou et al 2005). Geophysical methods were also used in large scale (Savvaidis et al 2000) providing information regarding bedrock depth on the western part Anthemountas river basin based on gravity and magnetic measurements. Thanasoulas (1983) with electrical soundings and Fikos et al (2000) with repeated ERT measurements focused on small scale surveys near the coastline and the city of Thermi.

In recent years the watershed management approach forced by 2000/60/EC, better known as water framework directive, pointed out the significance of a good understanding of hydrogeology in watershed management. In the case of Anthemountas river basin the available data revealed a very complex system of aquifers with significant extent in both lateral and vertical sense. Understanding the interaction among these underground water bodies will allow better planning and management of water resources. A large scale geophysical investigation focusing on the area west of Vasilika vil- 

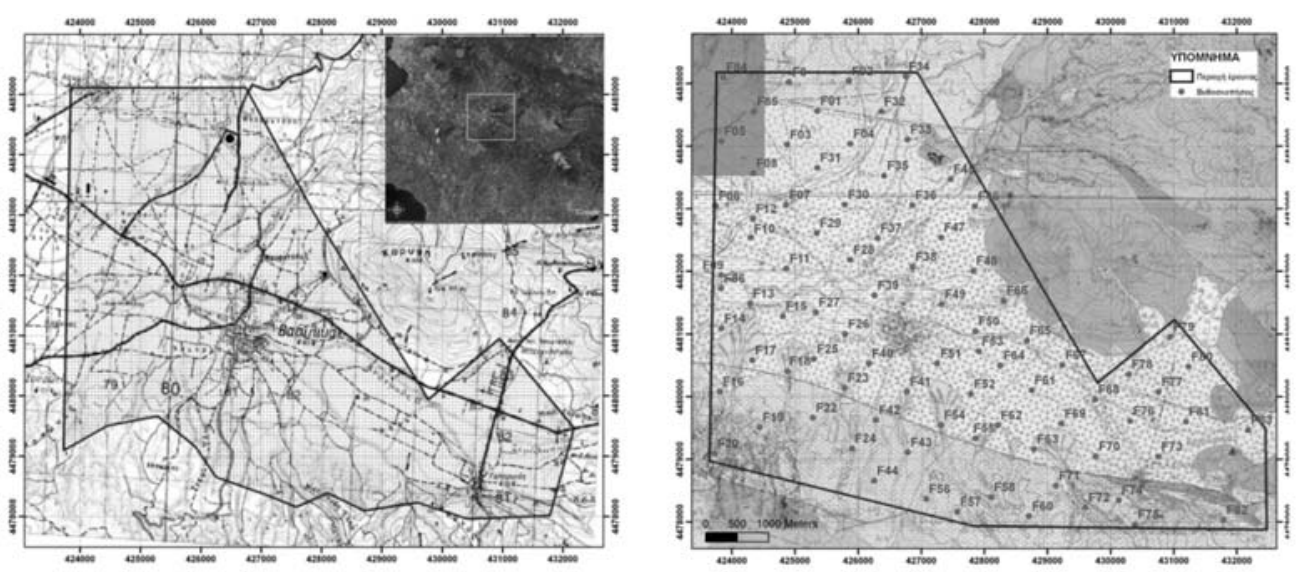

Fig. 1: (left): Survey area shown on topography map and survey area with exact location of the VES is also shown on geological map provided by IGME (right).

lage up to the eastern limits of Galarino village was conducted as part of LIFE04ENV/GR/000099 WATER AGENTA project. Eighty five (85) vertical electrical soundings (VES) were executed in a nearly regular grid with a distance of 750 meters between adjacent VES, surveying an area of $36 \mathrm{~km}^{2}$ (Fig.1), aiming to map the bedrock as well as sediments in smaller depths and examine their hydrogeological features.

\section{Geological - Hydrogeological setting}

According to the geology map provided by IGME (1:50000) the study area is covered with sediments deposits consisting of: i) Valley deposits: sandy clay, ii) Lower terrace system: gravels and sand under a clayey cover, iii) Upper terrace system: grits and pebbles with loam or sandy clay, iv) Fans of different age, v) Red clay series: red to brick red, silty clays with mica and calcareous concretionary bodies, while the area to the north and south are covered by vi) Limestones recrystallised, vii) Granodiorite, viii) Gabbro and ix) Dunites and peridotites. The location of the cross section shown on figure 2 can be seen on geology map of figure 1 and it becomes obvious that the area of interest is covered by sediments while the bedrock seen near point A2 dips due to tectonic faulting to the center of the basin to unknown depth. Similar behaviour can be observed near the north end of the cross section (towards point A3) where the bedrock (peridotites) is dipping to southeast direction. These fault systems also affect the red clay series creating a new valley that is filled with sand and gravel of the lower terrace system.

The hydrogeology varies significantly for the area of interest due to the anisotropy of the sediments of the basin. Their behaviour is driven mainly by their primary porosity and the secondary porosity caused from the faulting tectonics making it easier for water flow in certain areas. Data from more than 90 boreholes located in Anthemountas river basin were used to get a better understanding of the hydrogeological setting down to a depth of 200 meters although many of them stop in smaller depths. According to these data the sediments mainly consist of: sands, silts, clay, gravels and pebbles with large variations in their thickness and their granulometry. In these types of sediments the primary porosity varies between $20 \%$ and $35 \%$ and their permeability $\mathrm{K}$ from $10^{-8}-10^{-2} \mathrm{~m} / \mathrm{s}$ (Kallergis 1999) depended on the percentage of clay present. According to Theodossiou et al(2005), analysis of pumping tests in the eastern part of Anthemountas river basin, transmissivity $(\mathrm{T})$ ranges between $1,3 \times 10^{-}$ 


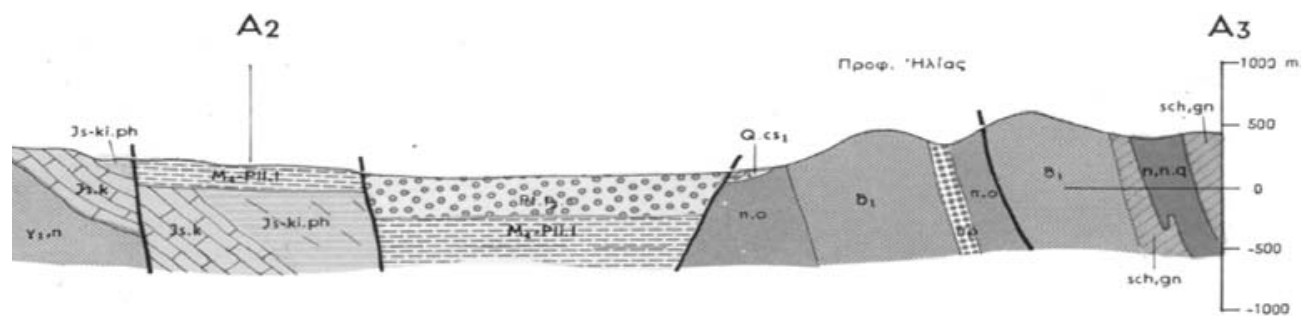

Fig. 2: Cross section A2 - A3 shown on geological map of figure 1, provided by IGME

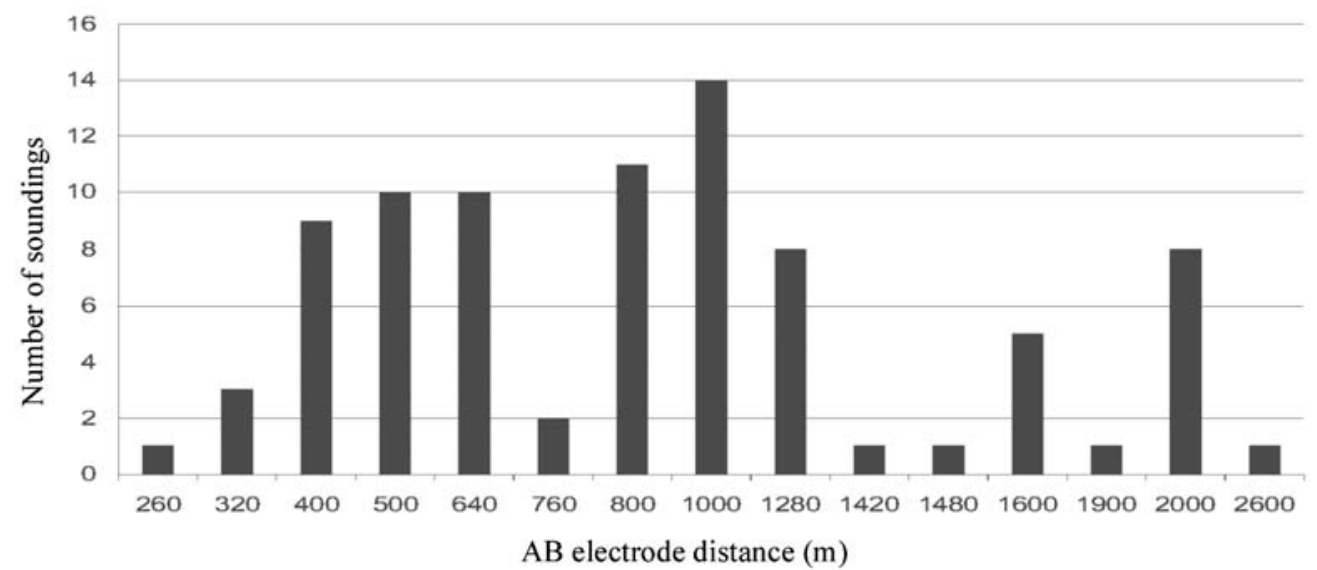

Fig. 3: Number of VES for different values of current electrode distance

${ }^{4} \mathrm{~m}^{2} / \mathrm{s}$ and $1,3 \times 10^{-3} \mathrm{~m}^{2} / \mathrm{s}$ and can be characterized as medium to high, hydraulic conductivity (K) ranges between $3,4 \times 10^{-6} \mathrm{~m} / \mathrm{s}$ and $2,9 \times 10^{-5} \mathrm{~m} / \mathrm{s}$ reflecting permeable formations of medium conductivity and storativity $(\mathrm{S})$ ranges between $4,3 \times 10^{-4}$ and $6,2 \times 10^{-2}$.

In the above mentioned formations, there is a complex system of aquifers that develop in the permeable sediments and which is characterised by significant anisotropy. In the area of interest two different aquifers can be identified based on the existing information: a) an unconfined aquifer in the depths of 10 to $30-40$ meters and b) a confined aquifer located deeper ( $>50$ meters) that is known to continue down to a depth of more than 200 meters but the majority of the existing hydro wells do not provide information deeper than 150 meters.

\section{Geophysical investigation}

\subsection{VES Field Data and interpretation}

A grid of 85 VES was planned and the exact location of each VES can be seen on Fig. 1. Each set of measurements was complete only after the bedrock could be identified in the sounding and that is why the current electrode distance AB varied between 260 meters and 2600 meters (Fig. 3). Measurements were taken with Syscal (V11.4) IRIS instrument and the IPI2WIN software (distributed by Geoscan-M Ltd) has been used for the inversion of field data. The initial model for the inversion was extracted by the use of theoretical curves for Sclhuberger soundings and the final RMS values varied between $0,5 \%$ and $7 \%$. 


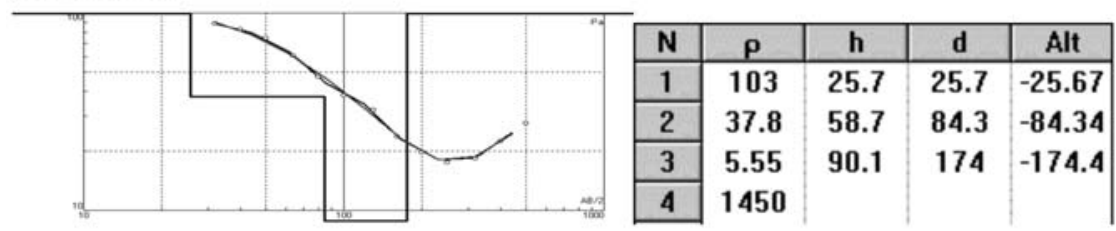

Sounding F03

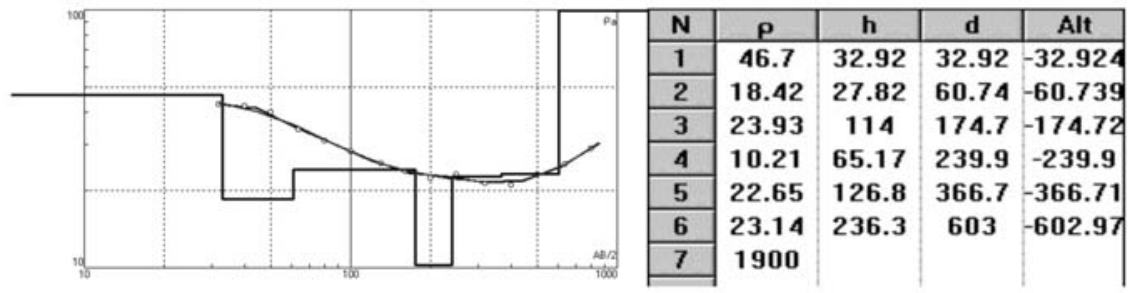

Sounding F07

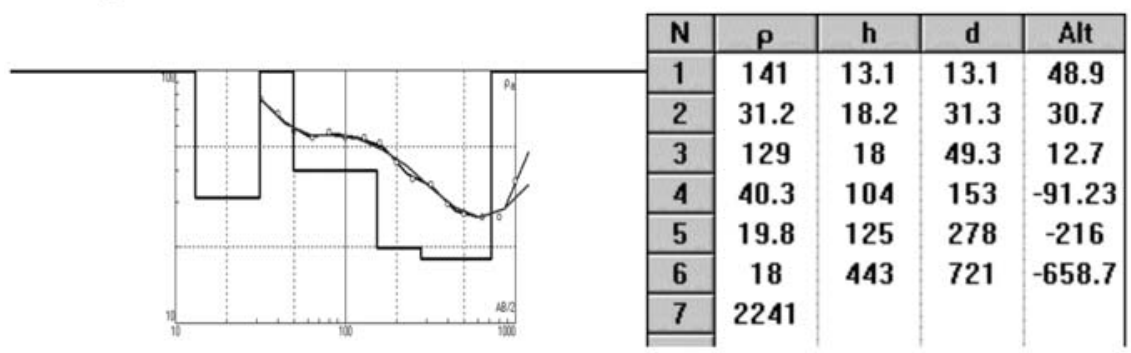

Sounding F15

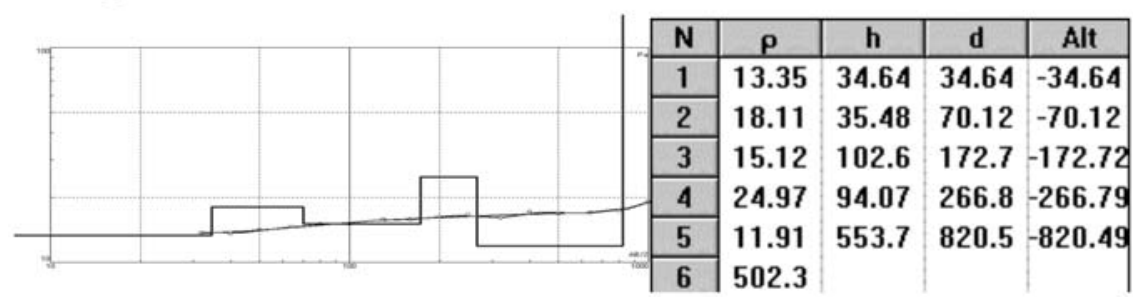

Sounding F32

Fig. 4: Example of interpretation for 4 representative VES measured in the survey.

Some typical examples of the results are presented in Fig. 4 where the reader can see the original measurements along with the resulting curve and the corresponding table of resistivity (Q), thickness (h), relative (to the surface) depth (d) and absolute elevation of the floor (Alt)of each identified layer. As it can be seen for example on sounding F15, the depth of investigation is more than 820 meters and the deeper identified layer appears with high resistivity ( $\varrho=502 \mathrm{Ohm}-\mathrm{m})$ and can be interpreted as the bedrock beneath the basin's sediments.

\subsection{Analysis and evaluation}

The resistivity values range from very few to few thousands ohm-m. This range corresponds to the large range of range of sediments and rock present in the area. Based on literature and on previous 
Table 1.

\begin{tabular}{|c|c|c|}
\hline Resistivity (Ohm-m) & Assumed formation & Colour Scale \\
\hline $0-10$ & Clay & A \\
\hline $10-20$ & Sandy clay with possible gravel & B \\
\hline $20-30$ & Sand with clay and gravel layers & $\mathrm{C}$ \\
\hline $30-50$ & Pebbles and gravel with water & $\mathrm{D}$ \\
\hline $50-80$ & Marl or weak conglomerate & $\mathrm{E}$ \\
\hline $80-150$ & Weathered bedrock & $\mathrm{F}$ \\
\hline$>150$ & Bedrock & $\mathrm{G}$ \\
\hline
\end{tabular}
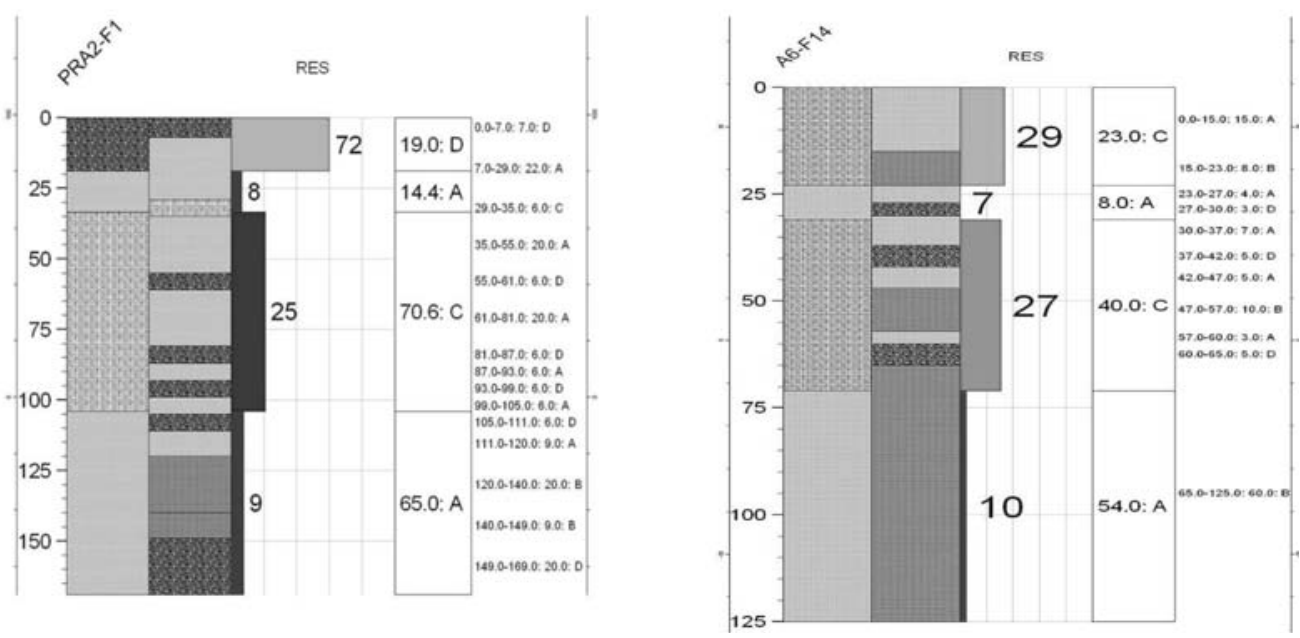

Fig. 5: Examples of calibration of table 1 based on borehole data near VES location.

experience, we created seven different groups corresponding to seven different formations, in order to evaluate the resistivity values.

To evaluate and further calibrate this table we compared soundings results with borehole data in 11 cases where the distance between borehole and VES location was small. Examples of these comparisons are shown in Fig. 5 where for each case we can see (in columns from left to right) formations based on colour scale from table 1 , lithostratigraphy, formation resistivity value, layer thickness and on the most right column the ceiling and bottom of each formation based on the borehole data and the corresponding formation from Table 1 .

Following this analysis we evaluated the results by creating pseudo-2D slices from adjacent VES, describing the variation of resistivity in 4 different orientation groups, more specifically we created 15 $\mathrm{N}-\mathrm{S}$ oriented slices, $13 \mathrm{NE}-\mathrm{SW}$ oriented slices, $6 \mathrm{NW}-\mathrm{SE}$ oriented slices and $4 \mathrm{E}-\mathrm{W}$ oriented slices. Chosen examples of some of them are shown in the following figures where the horizontal axis shows distance along the line and vertical axis shows absolute altitude. In each figure, on the left part we see the location of the shown line on the geology map and on the right part the 2D pseudosection of apparent resistivity (top) and the true resistivity (bottom). Table's 1 relation between resistivity value and 

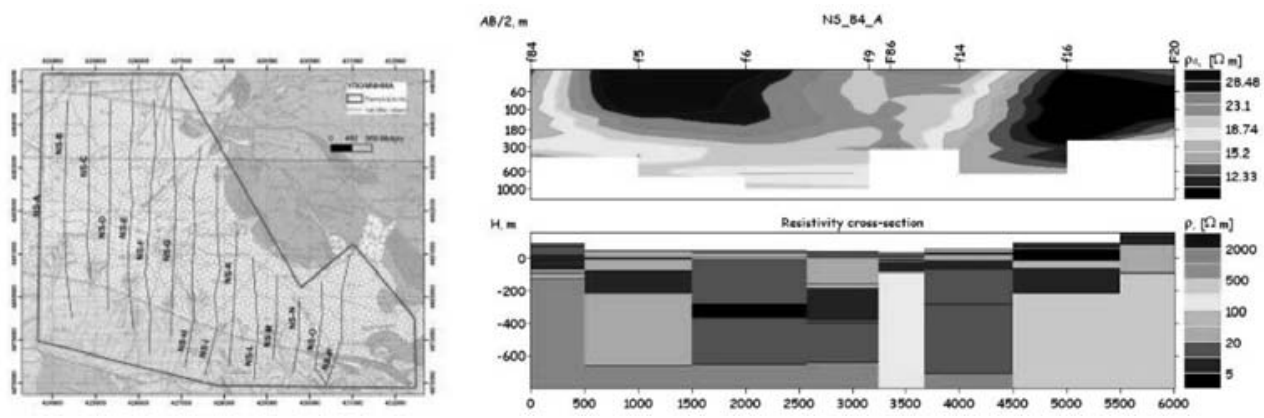

Fig. 6: N-S oriented vertical pseudosection A
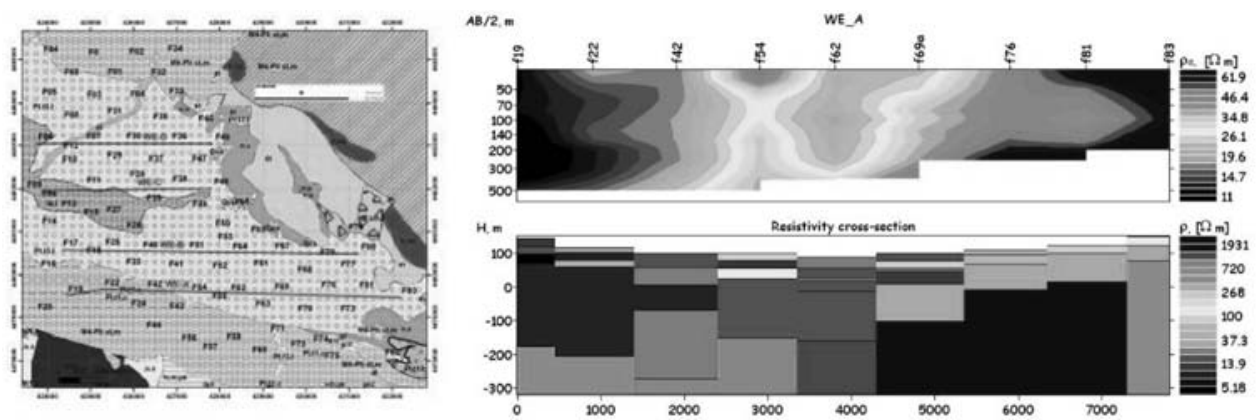

Fig. 7: W-E oriented vertical pseudosection A

different geological formation can be used here for better understanding of these images. In general the bedrock shows high resistivity $(\sim 500 \mathrm{Ohm}-\mathrm{m})$ and appears with colours range from orange to red. Sediment formations have different colours with special hydrogeological interest in those with values from 20 to $50 \mathrm{Ohm}-\mathrm{m}$ (blue and light blue colours). Black represents clay formations with no hydrogeological interest while green may represent marl formations that may have some interest in those cases where faults have created cracks capable to host underground water.

In the northern part of pseudosection A we can see the sudden change of the depth of bedrock from 160 meters (F84) to more than 600 (F5). This can only be explained by the existence of a fault which is in agreement with the tectonic mapping of the area (Tranos et al, 2004). Same is observed also in the southern part of the pseudosection between F20 and F16 where the bedrock again appears to drop in depths greater than 600 meters due to another fault, also identified by Tranos et al (2004). Another important feature in the same picture is that the bedrock on the southern part appears relatively much lower values than the bedrock on the northern part. This is due to the fact that to the north, the bedrock consists of granite or peridotites while to the south the bedrock probably consists of calcareous rocks and/or schist.

In same way in Fig. 7 we see a typical W-E vertical pseudosection that reveals the way the bedrock dips to the west, also changing due to tectonic contact to calcareous rocks or schist in the western part. In smaller depths (higher altitudes) the stratigraphy appears to have a clear lateral transition.

Similarly, horizontal slices at various altitudes (depths) have been created in order to have a better way to observe the lateral variations of the stratigraphy in the area of interest and identify specific areas of better hydrogeological characteristics. In this attempt, we created two maps (Fig. 8.) show- 

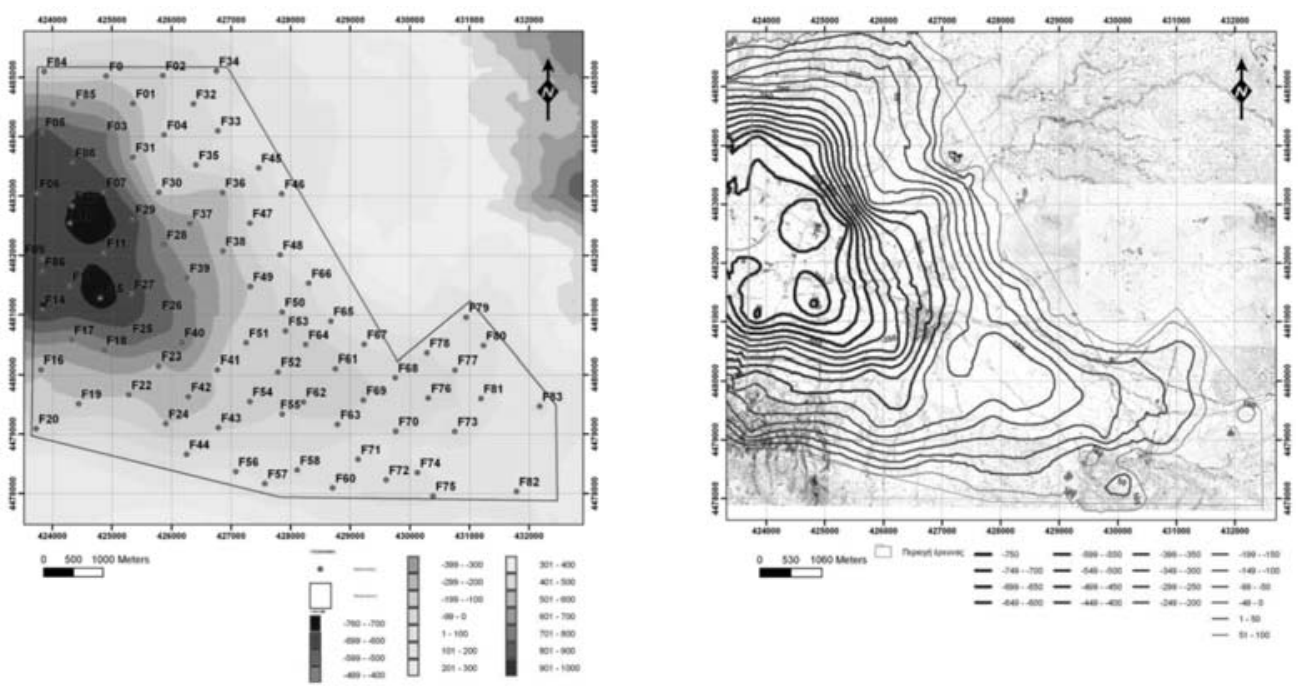

Fig. 8: Map of the expected altitude of the bedrock ceiling (left image) and the isodepth lines (right image) in the studied area.

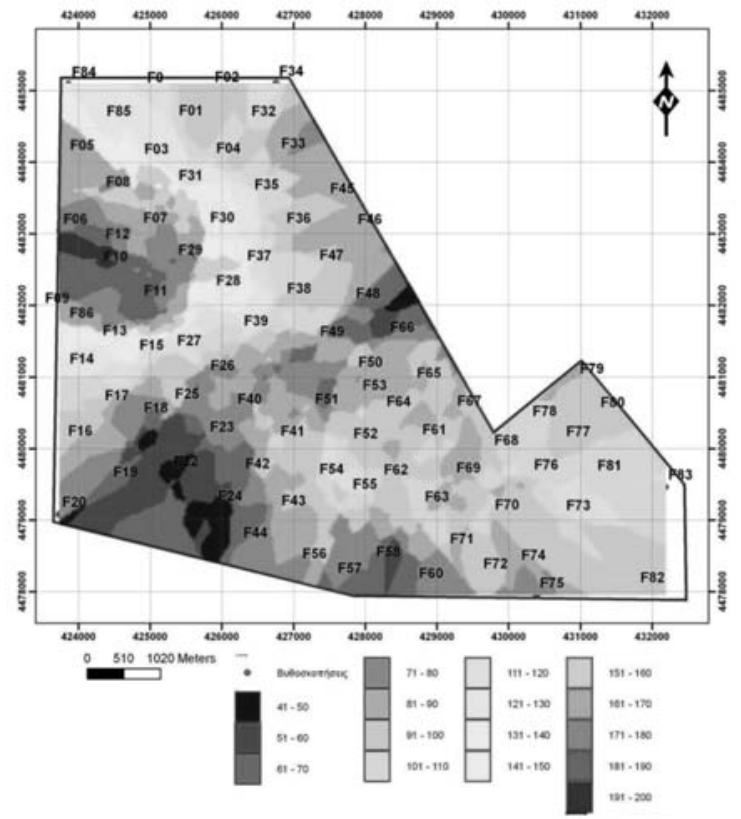

Fig. 9: Map of the expected thickness of formations $\mathrm{C}, \mathrm{D}$ and $\mathrm{E}$ down to depth of 300 meters in the studied area.

ing the altitude and depth of the bedrock ceiling in the sense that all sediments above the bedrock can potentially be exploited for water resources. However, since realistically most hydrowells don't drill deeper than 300 meters we examined the first 300 meters depth in the investigated area. To do this, we examined once again the formations of Table 1 and chose formations $C$ (Sand with clay with gravel layers) and D (Pebbles and gravel with water) as the most promising possible water resources. Formation E (Marl or weak conglomerate) was also accounted for due to the fact that tectonic reasons may increase its effective porosity. 
Table 2.

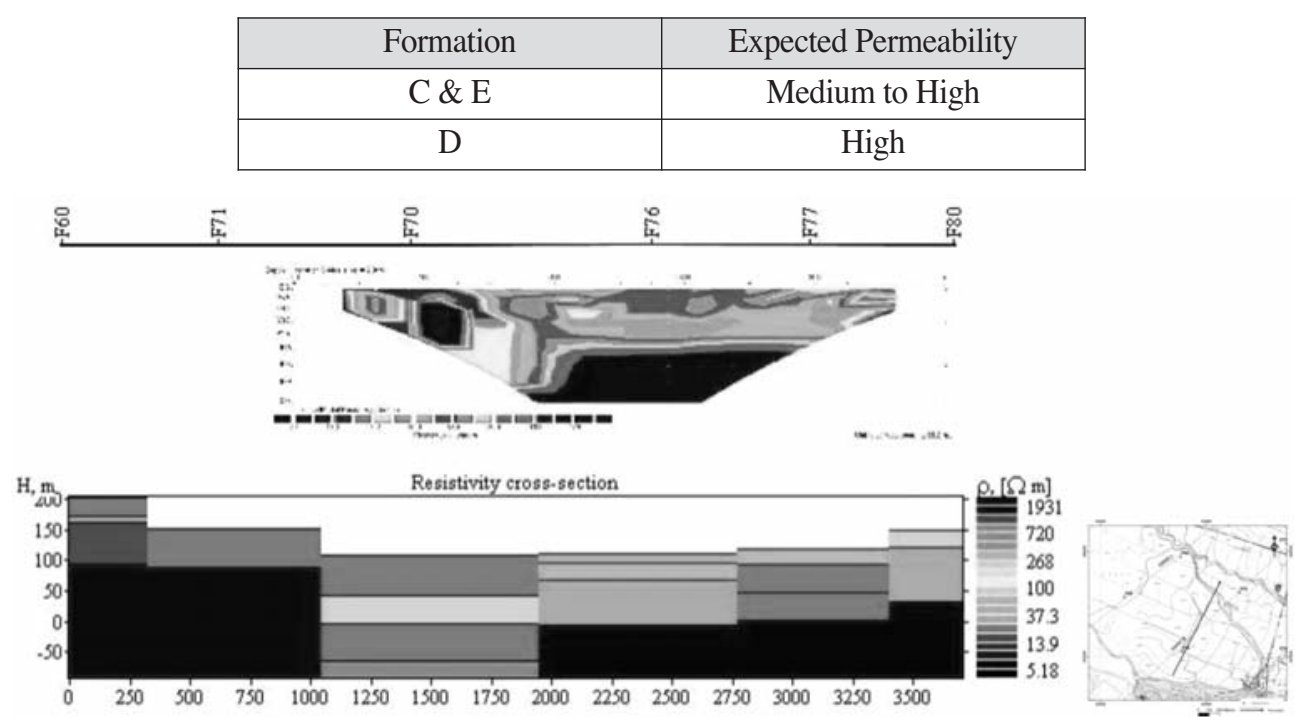

Fig. 10: Results of the ERT measured in the area shown on the top right image. The image on the left shows the pseudosection created from the adjacent VES along with the ERT inversion.

Based on typical permeability values for sediments (Kallergis 1999) we characterized the three formations (C, D and E) in terms of expected permeability (Table 2) and created maps (Fig. 9) showing the expected total thickness of these formations down to 300 meters depth.

\subsection{Electrical Resistivity Tomography data and interpretation}

The above mentioned analysis in two dimensional was based on adjacent 1D VES. In order to validate the vertical pseudosections we applied an electrical resistivity tomography (ERT) almost parallel to one vertical pseudosection. The location (Fig. 10) was selected based on the expected (from VES and borehole data) small depth of the bedrock since we know that the maximum depth of investigation with the ERT measurements couldn't be greater than approximately 250 meters.

The ERT result shows that the common part of the two sections is similar. The depth of the bedrock is around 150 meters in both cases. Furthermore the change of depth of the bedrock observed somewhere between F76 and F70 is clearly seen in the ERT approximately at the 450 meter of the ERT line.

\section{Conclusions-Results}

The results shown in this work show that when studying river basins with concern to water management and decision making VES can be a very useful tool. In the case of Anthemountas river basin:

i) The depth of bedrock surface, in the examined area, has been mapped even at depths greater than 800 meters west of Vassilika village (Fig. 11).

ii) The slope of bedrock depth reveals the location of possible fault lines and therefore providing useful geological information.

Moreover the analysis of sediments resistivity values reveals the following:

iii) There is significant anisotropy of the sediments due to change of the sediments sorting.

iv) Primary hydraulic continuity is often interrupted however near fault lines the operative porosity increases. 


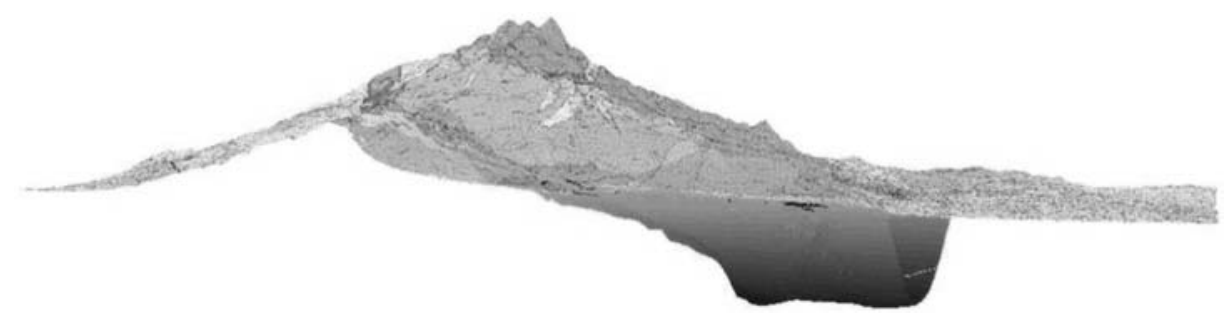

Fig. 11: Three dimensional image showing the bedrock surface dipping west (view from NW).

v) In the sediments examined, the percolation of water cannot be vertical revealing the significant role of inflow from margins of the basin.

vi) The area between the two water bodies developed west and east of the Vassilika and Galarinos villages is occupied by sediments with average to very good permeability thus allowing hydraulic communication.

vii) Moving from east to west near Vassilika significant clay layers are identified explaining the existence of confined and unconfined aquifers as we move further west.

The above conclusions offer important information for a large area of the basin, allowing a better understanding of the hydrogeological model and thus allowing scientists to plan water resources management.

\section{Acknowledgments}

Writers would like to thank Development Agency of Eastern Thessaloniki (ANATOLIKI S.A.) for providing large amount of borehole data and financing the survey through LIFE04ENV/GR/000099 WATER AGENTA project.

\section{References}

Alexei A. Bobachev, Igor. N. Modin, Vladimir A. Shevnin 1990-2001. Geoscan-M Ltd., Moscow, Russia. Available online at: http://www.geol.msu.ru/deps/geophys/ipi2win.htm

Fikos I, Vargemezis G., Tsokas G.N., Hatzidimitriu P. and Dimopoulos G., Diachronic study of free aquifers using the method of electric tomography: a case study in northern Greece, European Journal of Environmental and Engineering Geophysics 7 (2002), pp. 185-193

Savvaidis A.S., Tsokas G.N., Papazachos C.B., Kontopoulou D. 2000. A geophysical study of the ophiolite complex and the sedimentary basins in the northwest part of the Chalkidiki peninsula $(\mathrm{N}$. Greece). Surveys in Geophysics, 21, 567-595

Theodossiou N., Latinopoulos P. 2005. Evaluation and optimization of groundwater observation networks using the Kriging methodology, July 2005. Available online at: www.sciencedirect.com

Tranos M.D., Meladiotis I.D. and Tsolakopoulos E.P. 2004. Geometrical characteristics, scaling properties and seismic behavior of the faulting of the Chortiatis region and Anthemountas basin (Northern Greece), 5th International Symposium on Eastern Mediterranean Geology, Thessaloniki, Greece, 1420 April 2004

Thanassoulas C. 1983. Geophysical study of Anthemountas basin (V.E.S.), IGME (in Greek).

IGME 1996. Qualitative examination of surface and underground water of prefecture of Thessaloniki, IGME Dept. of Thessaloniki (in Greek).

Kallergis G.A. 1999. Applied-Environmental Hydrogeology, Technical Champer of Greece, pp330 (in Greek) Nagoulis Ath. 1998. Hydrological study of Anthemountas basin, ANATOLIKI S.A. (in Greek) 